\title{
Nedocromil sodium in adults with asthma dependent on inhaled corticosteroids: a double blind, placebo controlled study
}

\author{
MICHAEL F BONE, M MICHAEL KUBIK, NIALL P KEANEY, \\ GEOFFREY D SUMMERS, C KEVIN CONNOLLY, P SHERWOOD BURGE, \\ RICHARD G DENT, GEOFFREY W ALLAN
}

From Russells Hall and Burton Road Hospitals, Dudley; Sunderland Royal Infirmary, Sunderland; Kidderminster General Hospital, Kidderminster; Darlington Memorial Hospital, Darlington; Solihull Hospital, Solihull; Hertford County Hospital, Hertford; and Ruchill Hospital, Glasgow

ABSTRACT Eighty nine adults with asthma who were receiving inhaled corticosteroid and $\vec{\phi}$ bronchodilator treatment took part in a double blind, randomised, placebo controlled trial of nedocromil sodium, $4 \mathrm{mg}$ four times daily by inhalation. During a run in period of two to four week corticosteroid treatment was reduced when possible to produce a comparable level of symptoms across the trial population. The test treatment was then taken for four weeks, with the severity o $90^{\circ}$ asthma recorded daily by patients and assessed at two weekly hospital visits. There was ap improvement in symptoms in the patients taking nedocromil sodium by comparison with those having the placebo, the differences being significant for diary card PEF readings, asthma symptom scores, and bronchodilator usage at night. The mean difference between the two groups was $181 / \mathrm{mi}$ for PEF, 0.42 for daytime asthma score, and 1.73 puffs in 24 hours for bronchodilator usage. Thes results suggest that asthmatic patients who require inhaled steroids show better control of theif asthma with the addition of nedocromil sodium than of placebo over a four week period afte reduction of the dosage of their inhaled steroids.

\section{Introduction}

Nedocromil sodium, a pyranoquinoline dicarboxylate with anti-inflammatory activity, ${ }^{1}$ has been developed for use in the treatment of reversible obstructive airways disease. ${ }^{2}$ It has been shown to inhibit early and late reactions to antigen challenge in asthmatic patients $^{34}$ and to inhibit bronchoconstriction in response to exercise, ${ }^{5}$ inhaled sulphur dioxide, ${ }^{6}$ cold air, ${ }^{7}$ fog, ${ }^{8}$ and adenosine. ${ }^{9}$ Preliminary trials have shown its therapeutic efficacy ${ }^{1011}$ and ability to reduce airway hyperresponsiveness to histamine. ${ }^{12}$

This study was designed to assess the therapeutic efficacy and safety of nedocromil sodium, compared with placebo, in the treatment of adults with asthma who are dependent on inhaled corticosteroids. Although inhaled corticosteroids are usually well tolerated and very effective, they are occasionally associated with topical side effects such as oral

Address for reprint requests: Dr Michael F Bone, Russells Hall Hospital, Dudley, West Midlands DY1 2HQ.

Accepted 14 April 1989 candidiasis and vocal cord myopathy and at highe doses the possibility of systemic side effects cannot be ruled out. ${ }^{1314}$ We set out to determine whether nedocromil sodium, as a non-steroidal topical anti 3 asthma agent, could partially replace inhaled steroid\$ and offer an alternative form of preventive treatmen? for control of moderately severe asthma in adult patients. When a new non-bronchodilator treatmen for asthma is being assessed over a relatively shor period, it is difficult to provide the conditions whereby such patients, with asthma that is generally wels controlled by their regular treatment, can show a therapeutic response. In this trial this was achieved by reducing maintenance medication to produce an in $-\frac{\omega}{-}$ creased and fairly uniform level of symptoms before randomisation of the patients to the treatment an\& placebo groups of the trial.

\section{Methods}

PATIENTS

Adults were recruited into the study if they had diagnosis of mild or moderate asthma based on 
clinical history of at least 12 months, and if they were receiving inhaled corticosteroids and bronchodilator treatment to control symptoms. None of the patients had required regular oral corticosteroids or had used sodium cromoglycate during the previous three months. Airways obstruction was shown to be reversible by an improvement in $\mathrm{FEV}_{1}$ of at least $15 \%$ after inhalation of $200 \mu \mathrm{g}$ of salbutamol, either at admission or within the last 12 months. Asthma was classed as atopic if the patient had a positive skin test response to one or more allergens or had raised IgE concentrations and non-atopic if no allergic cause was identified.

The patients selected for trial treatment were cooperative and gave written, informed consent. Individuals with appreciable cardiovascular, renal, or hepatic disease were not admitted, nor were women who were pregnant or breast feeding.

\section{TRIAL DESIGN}

The trial was a four week, double blind comparative study, conducted on a multicentre basis with the approval of the appropriate local ethical committees.

During an initial two week open baseline period patients continued their regular treatment, which included at least an inhaled corticosteroid and an inhaled bronchodilator, and kept daily diary cards on which they recorded symptom scores, peak expiratory flow (PEF), and use of medications. Symptoms were recorded as night time asthma, morning tightness, daytime asthma, and cough, on a five point scale from 0 (no symptoms) to 4 (very severe symptoms). PEF was measured in the morning, afternoon, and evening with a mini-Wright peak flow meter; the highest of three measurements on each occasion was recorded.

After the baseline period patients reduced their daily inhaled corticosteroid dosage by half and entered a two week run in period, when they were observed for a predetermined increase in symptoms (adding 10 or more to the total symptom score (maximum possible $=112$ ) over the second week). If reducing the inhaled steroid dose led to severe deterioration of the patient's condition, the baseline dosage was restored and subsequently maintained throughout the trial period. If no change occurred, the entire run in procedure was repeated, the dose of inhaled steroid again being halved. Subjects still failing to show the required increase in symptoms were then excluded from the trial. Patients entered into the study were randomised in blocks of six, by coding sheet, to received additional medication with either nedocromil sodium or placebo for the four week trial period.

During the trial patients were seen after two and four weeks at the clinic, when diary cards were checked by the investigator, who also assessed the severity of asthma (0-4 scale), carried out pulmonary function tests (PEF), one second forced expiratory volume $\left(\right.$ FEV $\left._{1}\right)$, forced vital capacity (FVC)) at the same time of day for all visits and at least four hours after the last bronchodilator dose, and noted any unusual symptoms described by the patient. At the final visit the patient's and clinician's opinions of the effectiveness of the trial treatment were recorded on a five point scale going from 1 (very effective) to 5 (made condition worse).

\section{MEDICATION}

Nedocromil sodium, $2 \mathrm{mg}$ per actuation, or matched placebo were administered by metered dose pressurised aerosol through an open tube spacer, designed to help coordination of inhalation and improve topical delivery of the drug in asthmatic patients. Two inhalations were made four times daily throughout the four week trial period.

Other medication taken throughout the trial consisted of the daily dose of inhaled corticosteroid established during the run in period and an inhaled bronchodilator to be taken as required to control symptoms. Regular oral bronchodilator treatment was permitted during the trial, but deterioration in asthma requiring oral corticosteroids or increased usage of inhaled corticosteroids was regarded as failure of the trial treatment and the patient was withdrawn. Thus only the dose of inhaled bronchodilator could be varied during the test treatment period.

\section{STATISTICAL ANALYSIS}

Evaluation of the effect of treatment in each group was based on change from the run in period, using the mean of each two week period for diary card measurements. The effect of treatment with nedocromil sodium was assessed by comparing changes from the run in period for the different measures of asthma severity between the nedocromil sodium and the placebo group. Lung function changes were analysed by Student's $t$ test. Non-parametric analysis (Mann-Whitney $U$ test) was used for symptom severity scores, bronchodilator usage, and final opinions of treatment. Differences were considered to be significant where $p \leqslant 0.05$.

We included patients withdrawn through lack of a treatment effect in the end point analysis, taking the means of the last three days before withdrawal for diary card data and assigning extreme scores for asthma severity and global assessments. When patients were withdrawn for other reasons, data were included up to the point of withdrawal provided that they had used the trial treatment for more than five days.

\section{Results}

CORTICOSTEROID REDUCTION

Of 131 patients initially recruited, 32 were excluded 
Table 1 Characteristics of patients on admission to the study (values are numbers of patients except where stated otherwise)

\begin{tabular}{|c|c|c|}
\hline & $\begin{array}{l}\text { Nedocromil sodium } \\
(n=43)\end{array}$ & $\begin{array}{l}\text { Placebo } \\
(n=46)\end{array}$ \\
\hline $\begin{array}{c}\text { Age (y) } \\
\text { Mean } \\
\text { Range }\end{array}$ & $\begin{array}{l}49 \\
16-69\end{array}$ & $\begin{array}{l}45 \\
17-70\end{array}$ \\
\hline $\begin{array}{l}\text { Sex } \\
\text { Male } \\
\text { Female }\end{array}$ & $\begin{array}{l}29 \\
14\end{array}$ & $\begin{array}{l}24 \\
22\end{array}$ \\
\hline $\begin{array}{l}\text { Asthma } \\
\text { Duration (y) } \\
\text { Mean } \\
\text { Range } \\
\text { Type } \\
\text { Atopic } \\
\text { Non-atopic } \\
\text { Not recorded }\end{array}$ & $\begin{array}{l}14 \cdot 5 \\
1-50 \\
22 \\
20 \\
1\end{array}$ & $\begin{array}{l}11 \cdot 4 \\
1-38 \\
25 \\
20 \\
1\end{array}$ \\
\hline $\begin{array}{l}\text { Medications } \\
\text { Inhaled bronchodilator } \\
\text { Oral bronchodilator } \\
\text { Inhaled corticosteroid } \\
\text { Dose ( } \mu \mathrm{g} / \text { day) } \\
\text { Mean } \\
\text { Range }\end{array}$ & $\begin{array}{l}43 \\
23 \\
43 \\
725 \\
200-2000\end{array}$ & $\begin{array}{l}46 \\
21 \\
46 \\
660 \\
400-2000\end{array}$ \\
\hline
\end{tabular}

from entry when they failed to show an adequate rise in symptom score after reducing their inhaled corticosteroid dose by $75 \%$. Three further patients were excluded because of deteriorating asthma and seven for non-cooperation or other violation of protocol. Eighty nine patients satisfied the entry criteria at the end of the run in period. Of these, 54 had halved their dose of inhaled corticosteroids, 22 were taking one quarter of the original dose, and 13 who already had appreciable symptoms had no reduction in dose.

Forty three of those entering the trial were randomised to receive nedocromil sodium treatment and 46 placebo. The two groups were well matched for patients' characteristics and routine medication before the baseline period (table 1) and both groups reduced $\frac{}{9}$ their inhaled corticosteroids to a similar extent duringo the run in period. The mean daily dose was reduced $\overline{0}$ from 660 to $340 \mu \mathrm{g}$ (48\% reduction) in the placebo $\frac{\bar{\omega}}{\partial}$ group and from 725 to $390 \mu \mathrm{g}$ (46\% reduction) in the $\stackrel{\mathbb{Q}}{\propto}$ nedocromil sodium group; ( $\mathrm{p}<0.001$ by MannWhitney $U$ test for both groups).

\section{SAFETY AND TOLERABILITY}

Twenty two patients treated with nedocromil sodium? and 19 with placebo reported one or more unusual $x$ symptoms, all minor. The most common were taste $\overrightarrow{+}$ (four and three patients respectively) and sore throatoo (four and three); there were no differences between thes two groups.

Sixteen patients were withdrawn from the trial, six $\bigcirc$ taking nedocromil sodium and 10 taking placebo. Two of the former and seven of the latter were withdrawn because of deteriorating asthma as they requirede additional corticosteroid treatment and were regarded as treatment failures. Three patients in the nedocromile sodium group were withdrawn because of suspected adverse reactions: wheezing, sore throat, and nasalo obstruction with rhinitis (one of each). The remaining? withdrawals (one in the active treatment and three in the placebo group) were for non-cooperation with then protocol.

\section{DIARY CARD ANALYSIS}

During the run in period both treatment groups showed an increase in asthma symptoms and bron chodilator usage (figs 1 and 3 ) and a decrease in mean PEF at the three times of measurement (by 21-260 $1 / \mathrm{min}$; fig 2). The increase in severity of asthma after reduction of inhaled corticosteroids and before the test treatment was significant $(\mathrm{p}<0.01-<0.001)$ for alB

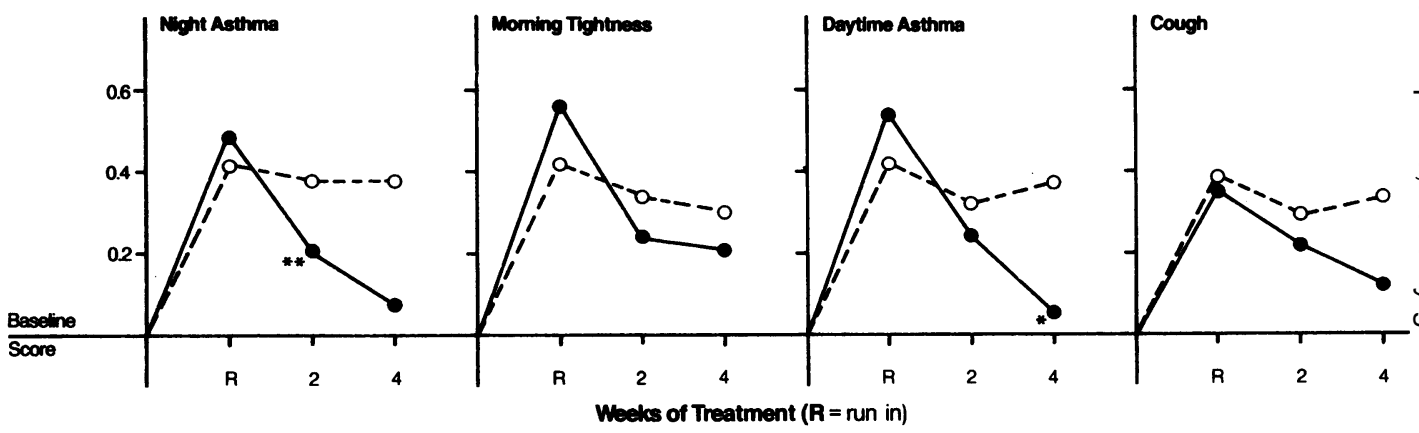

Fig 1 Changes from baseline diary card asthma symptom scores in patients treated with nedocromil sodium (O) and placebo (O). Mean baseline scores for the two groups were respectively 0.69 and 0.89 for night asthma, 1.27 and 1.40 for morning tightness, 0.86 and 1.00 for daytime asthma, 0.64 and 0.69 for cough. Treatment group comparison of changes from run in scores was calculated by the Mann-Whitney U test (significance: ${ }^{*} p<0.05 ;{ }^{* *} p<0.01$ ). 


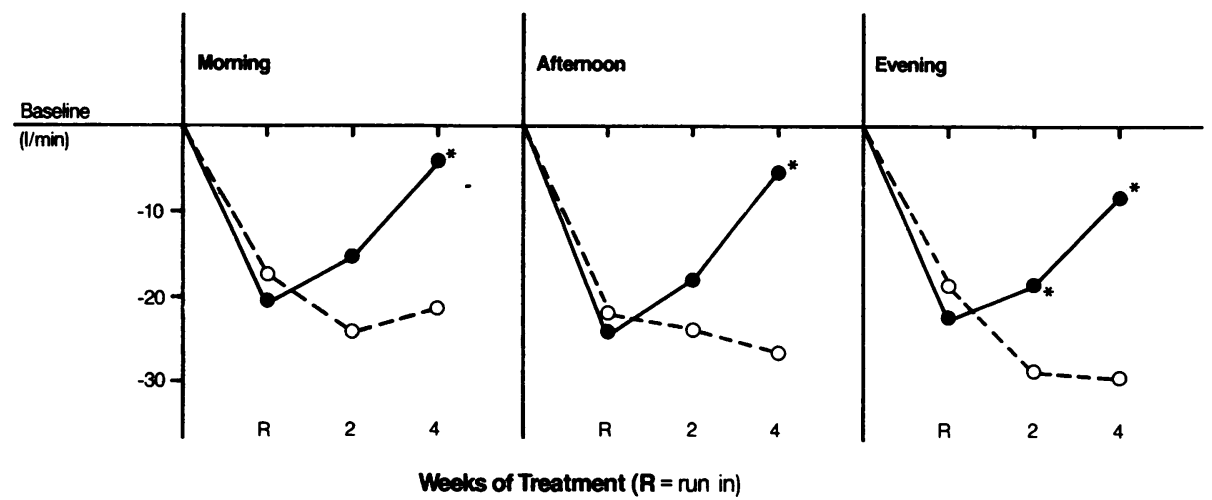

Fig 2 Changes from baseline diary card peak expiratory flow (PEF) measurements in patients treated with nedocromil sodium (O) and placebo (O). Mean (SD) baseline PEF values (l/min) for the two groups were respectively 319.5 (113.3) and 331.7 (118.5) for morning, 355.4 (119.8) and 356.3 (114.5) for afternoon, 347.0 (121.4) and 350.8 (116.1) for evening. Treatment group comparison of change from run in values was by Student's t test (significance: ${ }^{*} p<0.05$ ).

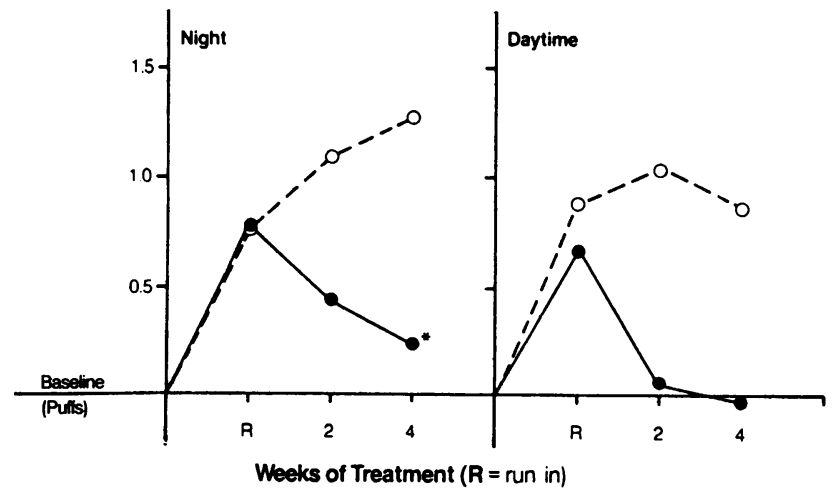

Fig 3 Changes in the "as required" use of inhaled bronchodilator during trial treatment with nedocromil sodium (O) and placebo (O). Baseline usage (mean pufs/ 12 hours) in the two groups was respectively 2.38 and 2.18 at night, 5.48 and 3.76 during the day. Comparison of treatment group changes from run in usage was by the Mann-Whitney U test (significance: $\left.{ }^{*} p<0.05\right)$.

Table 2 Results of pulmonary function tests at clinic visits: absolute values for the baseline and run in periods and change from the run in period in the two treatment groups at weeks 2 and 4

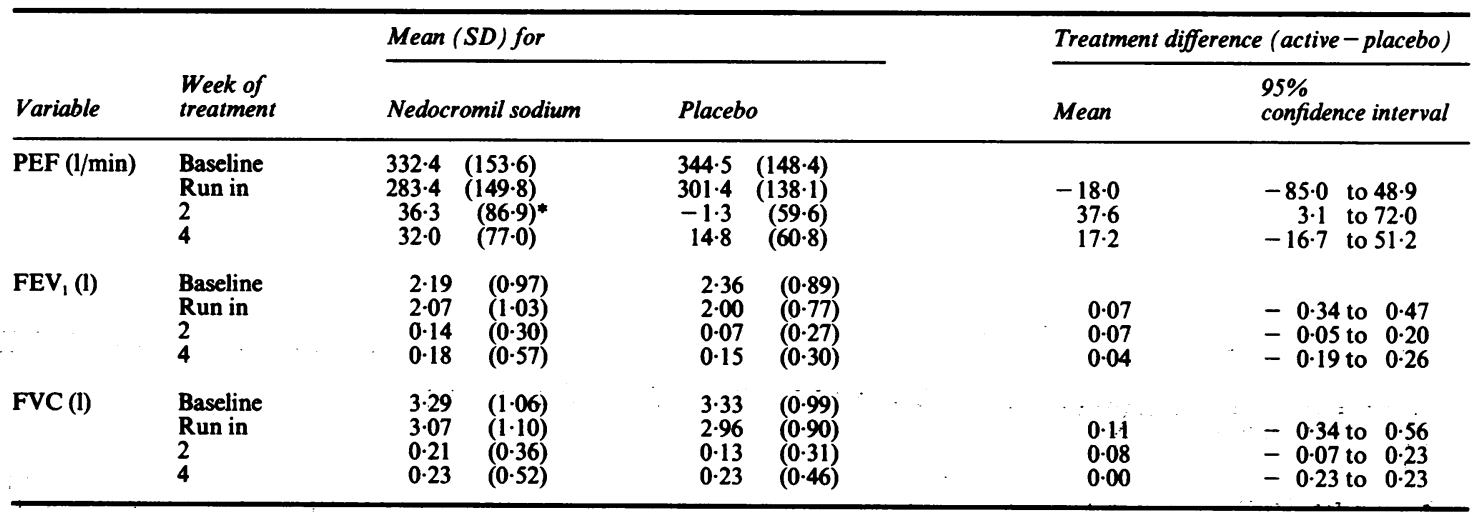

*Significance $\mathrm{p}<0.05$ by Student's $t$ test. 
variables in both groups, with no differences between the groups.

Diary card symptom scores (fig 1) improved in the patients treated with nedocromil sodium whereas those of placebo treated patients showed little change. The differences between the treatment groups were not large but were significant for night time symptoms in week $2(p=0.01)$ and for daytime asthma in week 4 $(p=0.03)$. The differences just failed to be significant for night symptoms in week $4(p=0.07)$, and for morning tightness $(p=0.07)$ and daytime asthma $(\mathrm{p}=0 \cdot 1)$ in week 2 .

Patients treated with nedocromil sodium showed a steady improvement in PEF from run in values (fig 2), but placebo treated patients continued the downward trend. At the end of the trial the overall mean daily PEF for nedocromil sodium patients was $18 \mathrm{l} / \mathrm{min}$ greater than that of placebo patients. The difference between the two groups was significant after two weeks for evening PEF $(p=0.03)$ and after four weeks for morning $(p=0.05)$, afternoon $(p=0.02)$, and evening $(p=0.03)$ measurements.

After four weeks' treatment the patients taking nedocromil sodium were having less inhaled bronchodilator (fig 3), whereas the placebo group tended to take more bronchodilator. The difference between the two groups was 1.73 puffs over 24 hours at week 4 , and was significant $(p=0.04)$ for nocturnal bronchodilator usage.

\section{CLINIC LUNG FUNCTION TESTS}

There was a significant reduction $(p<0.05-<0.001)$ in $F_{E V}, F V C$, and PEF measured in the clinic during the run in period. During the test treatment period all measurements tended to increase and, though this was more rapid in the nedocromil sodium group, the only significant difference was for PEF in week 2 (table 2).

\section{SUBJECTIVE ASSESSMENTS}

Final opinions showed that $16(42 \%)$ of the patients in the active group considered their treatment to be moderately or very effective, compared with $10(25 \%)$ of the placebo patients $(p=0 \cdot 10)$. The clinicians rated the treatment as moderately or very effective in 15 $(39 \%)$ of those having nedocromil sodium, compared with $10(25 \%)$ of the placebo group $(p=0 \cdot 13)$.

\section{Discussion}

This study was designed to test a new drug reported to have prophylactic efficacy in asthma. ${ }^{15}$ Patients were selected who were normally well managed with bronchodilators and inhaled corticosteroids, on which they were dependent for optimal control. This was achieved by admitting only those patients who showed a predetermined minimum increase in symptoms on reducing their routine inhaled corticosteroid treat- $\vec{F}$ ment by $50-75 \%$ or who were already suffering from symptoms to the same degree without reducing their? inhaled steroid. The protocol was thus designed to $\frac{\bar{\sigma}}{\bar{\omega}}$ cause minimal discomfort for the patient while leaving $\frac{\vec{\sigma}}{\widehat{\sigma}}$ scope for a measurable degree of symptomatic $\propto$ improvement with an effective treatment replacing $\tilde{N}^{\circ}$ inhaled steroid.

In general, the results vindicate the trial design. For example, though daily PEF decreased consistently $\vec{\omega}$ during steroid reduction, the actual fall was not large, averaging $23 \mathrm{l} / \mathrm{min}$ in the nedocromil sodium group $\times$ (inhaled steroid reduced by $335 \mu \mathrm{g}$ ) and $241 / \mathrm{min}$ in the + placebo group (inhaled steroid reduced by $320 \mu \mathrm{g}$ ). By 0 week 4 the active treatment group had improved by a daily mean of $18 \mathrm{l} / \mathrm{min}$, in contrast to a further slight ${ }_{\circ}^{+}$ reduction $(-41 / \mathrm{min})$ with placebo. In all, despite the $\mathcal{}$ subtle changes, nedocromil sodium had achieved $\rightarrow$ significant $(p<0.05)$ improvements over placebo for five of the nine variables assessed in the study at four weeks.

The small changes in symptoms were also of clinical $\vec{\oplus}$ importance, as evidenced by patients' and clinicians' perceptions of asthma severity and the effectiveness of the trial treatments. In addition, asthma symptoms with a reduced steroid maintenance dosage became $\frac{\partial}{\partial}$ serious enough to cause withdrawal from the trial at some stage in nine cases (two nedocromil sodium, $\frac{\circ}{\mathbb{Q}}$ seven placebo).

The protocol used here compares favourably with that of other studies designed to assess the potential of $\vec{J}$ nedocromil sodium as a treatment to replace inhaled corticosteroids in asthma. In studies in which inhaled steroid treatment was withdrawn totally, after a three week period of additional nedocromil sodium or $\underset{x}{\tilde{Q}}$ placebo, ${ }^{1617}$ there was a progressive deterioration in asthma over the subsequent nine weeks. Nedocromil 3 . sodium did not therefore compensate for abrupt steroid withdrawal, though in patients who required no more than $500 \mu \mathrm{g} /$ day of beclomethasoneo dipropionate $^{16}$ it was able to maintain a degree of $\supset$ symptomatic control after withdrawal of inhaledo steroids. In that study there was also some indication of benefit from nedocromil sodium during the initialos add on phase of treatment.

Evidence that nedocromil sodium can replace inhaled corticosteroids has come from studies where ${ }_{\sigma}$ steroid dosage was first reduced to a minimum before the start of the trial treatment ${ }^{1011}$ or even stopped completely before the baseline period. ${ }^{19}$ One advantage of reduction of inhaled steroid treatment before the trial is that patients entering the trial phase are ${ }_{0}^{-}$

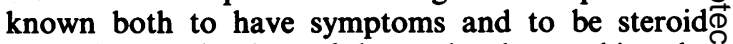
dependent at the time of the study, thus making the groups more homogeneous. Lal and colleagues $\frac{10}{\sigma}$ excluded nine patients from an original entry of $\mathbf{4 0}$ for 
this reason, and in the present study 32 of the 131 patients initially screened showed no increase in symptoms after reducing their inhaled steroid dose to one quarter, suggesting an unnecessarily high maintenance inhaled steroid dosage in many asthmatic patients.

A carry over effect after withdrawal of corticosteroids with high doses of inhaled beclomethasone ${ }^{20}$ may occur and might account for a delay in increasing symptom severity. The continued deterioration in peak flow rate and increase in night time bronchodilator usage in the placebo treated patients after the run in period (figs 2 and 3) would support this. The exclusion of any patients who did not show increased symptoms within two weeks of steroid reduction would reduce the impact of any carry over effect, which was then adequately controlled by the group comparative design.

In this placebo controlled study nedocromil sodium, $4 \mathrm{mg}$ four times daily by inhalation, provided a safe and effective adjunct to therapy for asthma in adult patients dependent on inhaled steroids. Before the start of the trial steroid intake was halved, giving an overall reduction of approximately $330 \mu \mathrm{g}$ of beclomethasone per day. The consequent increase in symptoms was largely reversed by four weeks' treatment with nedocromil sodium.

Support for this study, including all trial materials, was provided by Fisons PLC. We particularly acknowledge the careful data collection carried out by Hilary V Medley, clinical research scientist at Fisons.

\section{References}

1 Moqbel R, Cromwell O, Walsh GM, Wardlaw AJ, Kurlak L, Kay AB. Effects of nedocromil sodium (Tilade) on the activation of human eosinophils and neutrophils and the release of histamine from mast cells. Allergy 1988;43:268-76.

2 Cairns H, Orr TSC. The development of a new agent for the treatment of inflammatory/allergic conditions. Int Arch Allergy appl Immunol 1987;82:513-7.

3 Youngchaiyud P, Lee TB. Effect of nedocromil sodium on the immediate response to antigen challenge in asthmatic patients. Clin Allergy 1986;16:129-34.

4 Dahl R, Pedersen B. Influence of nedocromil sodium on the dual asthmatic reaction after allergen challenge; $a$ double-blind placebo controlled study. Eur J Respir Dis 1986;69(suppl 147):263-5.

5 Shaw RJ, Kay AB. Nedocromil, a mucosal and connective tissue mast cell stabiliser, inhibits exercise-induced asthma. Br J Dis Chest 1985;79:385-9.

6 Dixon CMS, Fuller RW, Barnes PJ. Effect of nedocromil sodium on sulphur dioxide induced bronchoconstriction. Thorax 1987;42:462-5.

7 Juniper EF, Kline PA, Morris MM, Hargreave FE. Airway constriction by isocapnic hyperventilation of cold, dry air: comparison of magnitude and duration of protection by nedocromil sodium and sodium cromoglycate. Clin Allergy 1987;17:523-8.

8 Robuschi M, Vaghi A, Simone P, Bianco S. Prevention of fog-induced bronchospasm by nedocromil sodium. Clin Allergy 1987;17:69-74.

9 Crimi E, Brusasco V, Brancatisano M, Losurdo E, Crimi P. Effect of nedocromil sodium on adenosine- and methacholine-induced bronchospasm in asthma. Clin Allergy 1987;17:135-41.

10 Lal S, Malhotra S, Gribben D, Hodder D. Nedocromil sodium: a new drug for the management of bronchial asthma. Thorax 1984;39:809-12.

11 Fyans PG, Chatterjee PC, Chatterjee SS. A trial comparing nedocromil sodium (Tilade ${ }^{(\mathrm{R})}$ ) and placebo in the management of bronchial asthma. Clin Allergy 1986; 16:505-11.

12 Dorward AJ, Roberts JA, Thomson NC. Effect of nedocromil sodium on histamine airway responsiveness in grass pollen sensitive asthmatics during the grass pollen season. Clin Allergy 1986;16:309-15.

13 König P. Inhaled corticosteroids. Their present and future role in the management of asthma. J Allergy Clin Immunol 1988;82:297-306.

14 Stead RJ, Cooke NJ. Adverse effects of inhaled corticosteroids. $\mathrm{Br}$ Med J 1989;298:403-4.

15 Gonzalez JP, Brogden RN. Nedocromil sodium. A preliminary review of its pharmacodynamic and pharmacokinetic properties, and therapeutic efficacy in the treatment of reversible obstructive airways disease. Drugs 1987;34:560-77.

16 Chadwick G, Lane DJ. A double-blind comparative trial of nedocromil sodium versus placebo as replacement therapy for inhaled corticosteroids in patients with bronchial asthma. Eur $J$ Respir Dis 1986;69(suppl 147):327-9.

17 Paananen M, Karakorpi T, Kreus KE. Withdrawal of inhaled corticosteroid under cover of nedocromil sodium. Eur J Respir Dis 1986;69(suppl 147):330-5.

18 Dorow P. A double-blind group comparative trial of nedocromil sodium and placebo in the management of bronchial asthma in steroid-dependent patients. Eur $J$ Respir Dis 1988;69(suppl 147):317-9.

19 Greif J, Fink G, Smorzik Y, Topilsky M, Bruderman I, Spitzer SA. A multicenter, double-blind, parallelgroup comparison of nedocromil sodium and placebo in the treatment of bronchial asthma. Chest (in press).

20 Weir DC, Gove RI, Robertson AS, Burge PS. Corticosteroid trials in non-asthmatic chronic airflow obstruction: comparison of oral prednisolone and inhaled beclomethasone dipropionate. Thorax (in press). 